\section{RMD Open}

Rheumatic \& Musculoskeletal Diseases

\title{
Osteoporosis in psoriatic arthritis: a cross-sectional study of an outpatient clinic population
}

\author{
Agnete Malm Gulati, ${ }^{1,2}$ Brigitte Michelsen, ${ }^{2,3}$ Andreas Diamantopoulos, ${ }^{4}$ \\ Berit Grandaunet, ${ }^{1}$ Øyvind Salvesen, ${ }^{5}$ Arthur Kavanaugh, ${ }^{6}$ Mari Hoff, ${ }^{1,2,7}$ \\ Glenn Haugeberg ${ }^{2,4}$
}

To cite: Gulati AM, Michelsen B, Diamantopoulos A, et al. Osteoporosis in psoriatic arthritis: a cross-sectional study of an outpatient clinic population. RMD Open 2018;4:e000631. doi:10.1136/ rmdopen-2017-000631

- Prepublication history and additional material for this paper are available online. To view these files, please visit the journal online (http://dx.doi.org/ 10.1136/10.1136/rmdopen2017-000631).

Received 7 December 2017 Revised 22 May 2018 Accepted 29 May 2018

\section{ABSTRACT}

Background The risk of osteoporosis in patients with psoriatic arthritis (PsA) still remains unclear. The aim of this study was to investigate bone mineral density (BMD) at the hip and lumbar spine measured by dualenergy X-ray absorptiometry in patients with PsA.

Methods From an outpatient clinic in southern Norway, 140 patients with PsA were consecutively recruited and assessed for osteoporosis as part of a prospective study from January 2013 to May 2014. An extensive data collection was performed including demographic data and measures reflecting disease activity and health status. Results Mean age was 52.4 years and 71 (50.7\%) were women. Median disease duration was 7.8 years. The proportion of patients with low BMD (defined as Z score $\leq-1.0 \mathrm{SD}$ ) was comparable to the expected value of $16 \%$, according to the normal distribution of the Z score in the population. Osteoporosis was only found in $6.4 \%(95 \%$ $\mathrm{Cl} 3 \%$ to $11 \%$ ) of the patients. No significant associations were found between BMD and disease activity measures. Conclusion The prevalence of PsA patients with osteoporosis or low BMD was low and in the range seen in the reference population. This supports that patients with PsA are not at high risk for osteoporosis compared with the general population. Therefore, clinicians may follow the general population guidelines for monitoring of osteoporosis for patients with PsA.

\section{BACKGROUND}

Psoriatic arthritis (PsA) is an inflammatory arthritis associated with psoriasis. The clinical presentation of PsA is heterogeneous and may involve both the peripheral joints and the axial skeleton (sacroiliitis or spondylitis) and also skin, nails and entheses. In PsA, activation of both osteoclasts and osteoblasts can be involved, and as a consequence, patients may show signs of both bone destruction and new bone formation. ${ }^{1}$ In rheumatoid arthritis (RA), osteoclast activation is dominating, and the increased risk of generalised bone loss and the development of osteoporosis is well established..$^{2-5}$ Data on systemic bone loss
Key messages

What is already known about this subject?

- The risk of osteoporosis in patients with psoriatic arthritis (PSA) in the biological treatment era still remains unclear.

What does this study add?

- In this study, bone mineral density (BMD) at the hip and lumbar spine was measured by dual-energy $X$-ray absorptiometry in 140 patients with PsA from an outpatient clinic.

- The prevalence of osteoporosis ( $\mathrm{T}$ score $\leq-2.5$ ) was low, and the prevalence of low BMD (Z score $\leq-1)$ was comparable to the range in the reference population.

How might this impact on clinical practice?

- These results support that patients with PSA are not at high risk for osteoporosis compared with the general population.

- Therefore, clinicians may follow the general population guidelines for monitoring of osteoporosis for patients with PSA.

in patients with PsA are conflicting and are likely highly dependent on patient selection. ${ }^{6}$ An association between PsA and osteoporosis has been reported, ${ }^{78}$ whereas others find comparable bone mineral density (BMD) in patients with PsA and the background population. $^{9-13}$ The major advances in pharmacological treatment of PsA, particularly the arrival of biologic therapies, have led to an improvement in controlling disease activity and inflammation, which may impact the systemic bone loss in patients with PsA. Thus in light of these improvements there is a need for updated data on the risk of osteoporosis in PsA.

In this cross-sectional study from a Norwegian outpatient clinic, we report the BMD measured with dual-energy X-ray 
absorptiometry (DXA) at the hip and lumbar spine in patients with PsA in the biological treatment era. Further, we wanted to identify demographic, clinical and treatment factors that might be associated with BMD in patients with PsA.

\section{METHODS}

\section{Study population}

Of the 581 patients carrying a diagnosis of PsA registered at the Department of Rheumatology outpatient clinic of the Hospital of Southern Norway Trust, Kristiansand, during the study period from January 2013 to May 2014, 471 fulfilled the Classification of Psoriatic Arthritis criteria. ${ }^{14}$ Of these, 141 patients were consecutively recruited at routine visits for more extensively investigation, and 140 patients, both men and women, had DXA scanning of lumbar spine and hip. ${ }^{15}$ All the included patients had peripheral inflammatory involvement clinically as patients with only axial manifestations were excluded. The included and non-included patients were similar in most disease activity measures including 28 swollen joint count; however, 28 tender joint count and disease activity score for 28 joints with erythrocyte sedimentation rate (ESR) (DAS 28) was marginally higher for the included patients. Also the included patients were younger than the non-included. A comparison of the included and non-included patients from the PsA cohort at Hospital of Southern Norway Trust has previously been described in detail. ${ }^{16}$ Informed consent was obtained according to the Declaration of Helsinki. The study was approved by the Regional Committee for Medical Research Ethics in South-Eastern Norway (REK number: 2012/101).

\section{Collection and measurement of data}

Data collection included demographics, clinical and laboratory measures, treatments and fracture history. The following data were recorded: age, sex, postmenopausal status, weight, height, body mass index (BMI), duration of PsA, smoking status (current or previous), alcohol consumption (more than three units pr day), ESR (Westergren's method), C-reactive protein (CRP, lowest detectable value $1 \mathrm{mg} / \mathrm{dL}$ ), level of physical activity (>1 time pr. week or $<1$ time pr. week), DAS 28, Bath Ankylosing Spondylitis Disease Activity Index (BASDAI), Maastricht Ankylosing Spondylitis Enthesitis Score (MASES), cutaneous involvement (Psoriasis Area Severity Index (PASI)), patient's global assessment (PGA), investigator's global assessment (IGA), tender joint count 68, swollen joint count 66, Modified Health Assessment Questionnaire (MHAQ), non-steroidal anti-inflammatory drug (NSAID) use, disease modifying antirheumatic drug (DMARD) use, tumour necrosis factor (TNF) inhibitors, glucocorticoid treatment (current use or ever use of $\geq 5 \mathrm{mg}>3$ months), vitamin $\mathrm{D}$ and calcium supplements and anti-osteoporotic treatment. Fragility fracture was defined as vertebral or peripheral fracture occurring spontaneously or caused by low-impact trauma at any time in the life of the subjects as reported by the patients. Blood samples were analysed by standard laboratory techniques at the participating hospital. Use of medications was self-reported by the patients.

\section{Bone density measurements}

BMD (as $\mathrm{g} / \mathrm{cm}^{2}$ ) was measured at the lumbar spine (L1-L4), and hip (femoral neck and total hip) by DXA (Lunar Prodigy, GE Healthcare). We preferably used measurements from the left hip. Scans from the right hip were used in five $(3.6 \%)$ patients because of missing values from the left hip. All participants had measurements of the lumbar spine. The DXA machine was stable during the whole study period and all DXA measurements were performed by experienced technicians. As a measure of BMD variability, the in vitro long-term coefficient of variance (CV) for the spine phantom was $0.62 \%$. The in vivo CV was $0.91 \%$ for $\mathrm{L} 1-\mathrm{L} 4$ measurements, $1.56 \%$ for left femoral neck and $0.88 \%$ for left total hip.

The T score (comparison with normal, young subjects of same sex) and $\mathrm{Z}$ score (comparison with age, sex and weight matched normal controls) were based on the reference values in the DXA machine provided by the manufacturer (NHANES). Further, we also calculated the percentage of patients with $\mathrm{T}$ score $\leq-2.5$ SDs and $\mathrm{Z}$ score $\leq-1.0 \mathrm{SD}$. The WHO definition was applied for osteoporosis ( $\mathrm{T}$ score $\leq-2.5 \mathrm{SD}$ ) and normal BMD ( $\mathrm{T}$ score $\geq-1.0 \mathrm{SD}) .{ }^{17}$

\section{Statistical analyses}

All statistical analyses were performed with SPSS for Mac V.21. Statistical significance level was defined as $\mathrm{p}<0.05$. To test whether data were normally distributed, we used $\mathrm{Q}-\mathrm{Q}$ plots. Continuous data are presented as mean with SD when normally distributed or median with IQR when non-normally distributed. CIs were used to assess the difference between the mean $\mathrm{Z}$ score at each anatomical site and the reference population data from the DXA machine provider. Assuming a normal distribution, the risk is $68 \%$ of being within $\pm 1 \mathrm{SD}$ of the mean $\mathrm{Z}$ score, thus, the expected proportion of $\mathrm{Z}$ scores $\leq-1.0$ $\mathrm{SD}$ in the reference population is $16 \%$ by default. The proportions of patients having a $\mathrm{Z}$ score of $\leq-1.0 \mathrm{SD}$ was compared with the expected value of $16 \%$ by a binomial test and the $95 \%$ CIs for the proportions of patients with $\mathrm{T}$ score $\leq-2.5$ and $\mathrm{Z}$ score $\leq-1.0$ were calculated. $\mathrm{T}$ score was compared between users and non-users of glucocorticoids and biological DMARDs with linear regression adjusting for age and sex.

Association between clinical and demographic factors and BMD was analysed using linear regression. Variables from the univariable analyses with a $\mathrm{p}$ value $\leq 0.10$ were included in a multivariable model, which also included sex and age regardless of the significance in the univariable analyses. For missing data, we excluded cases pairwise. This method excludes patients only if they have missing data required for the specific analysis. They are 
Table 1 Demographic and clinical variables of the 140 patients with psoriatic arthritis included ${ }^{*}$

\begin{tabular}{|c|c|c|c|}
\hline & $\begin{array}{l}\text { All patients with } \\
\text { psoriatic arthritis } \\
\mathrm{N}=140\end{array}$ & $\begin{array}{l}\text { Females } \\
\mathrm{N}=71\end{array}$ & $\begin{array}{l}\text { Males } \\
\mathrm{N}=69\end{array}$ \\
\hline Age, years, mean (SD) & $52.4(10.3)$ & $52.9(10.3)$ & $51.9(10.3)$ \\
\hline Female, n (\%) & $71(50.7)$ & NA & NA \\
\hline Postmenopausal, n (\%) & $34(24.3)$ & $34(47.9)$ & NA \\
\hline Weight, kg, mean (SD) & $82.5(14.7)$ & $79.2(13.6)$ & $91.9(13.0)$ \\
\hline Height, cm, mean (SD) & $174.0(8.8)$ & $168.2(6.5)$ & $180.0(6.6)$ \\
\hline $\mathrm{BMI}, \mathrm{kg} / \mathrm{m}^{2}$, mean (SD) & $28.2(4.2)$ & $28.0(4.8)$ & $28.4(3.6)$ \\
\hline Disease duration, median (IQR) & $7.8(9.3)$ & $7.6(8.8)$ & $7.8(10.4)$ \\
\hline \multicolumn{4}{|l|}{ Smoking, n (\%) } \\
\hline Current & $23(16.4)$ & $14(19.7)$ & $9(13.0)$ \\
\hline Previous & $72(51.8)$ & $33(46.5)$ & $39(56.5)$ \\
\hline Alcohol consumption (more than 3 units per day), $\mathrm{n}(\%)$ & $1(0.7)$ & 0 & $1(1.4)$ \\
\hline CRP, mg/L, median (IQR) & $2.0(4.0)$ & $2.0(3.0)$ & $3.0(6.0)$ \\
\hline ESR, mm/hour, median (IQR) & $13(15)$ & $16(16)$ & $10(11)$ \\
\hline Physical activity $\geq 1$ time per week, $n(\%)$ & $62(44.3)$ & $33(46.5)$ & $29(42.0)$ \\
\hline HLA B 27, n (\%) & $34(24.3)$ & $14(19.7)$ & $20(29.0)$ \\
\hline DAS 28, mean (SD) & $3.16(1.14)$ & $3.55(1.08)$ & $2.74(1.05)$ \\
\hline BASDAI, mean (SD) & $3.35(2.24)$ & $3.84(2.34)$ & $2.84(2.03)$ \\
\hline MASES, mean (SD) & $2.97(3.19)$ & $4.14(3.39)$ & $1.77(2.45)$ \\
\hline PASI, mean (SD) & $2.56(3.63)$ & $1.88(2.94)$ & $3.24(4.12)$ \\
\hline Patient global assessment, mean (SD) & $36.12(24.32)$ & $41.69(25.15)$ & $30.39(22.18)$ \\
\hline Investigator global assessment, mean (SD) & $14.56(12.11)$ & $14.69(11.69)$ & $14.43(11.00)$ \\
\hline TJC 68, median (IQR) & $6(14)$ & $8(16)$ & $4(9)$ \\
\hline SJC 66, median (IQR) & $0(1)$ & $0(1)$ & $0(1)$ \\
\hline MHAQ, mean (SD) & $0.43(0.40)$ & $0.50(0.44)$ & $0.35(0.33)$ \\
\hline Current use of NSAIDs, n (\%) & $45(32.1)$ & $24(33.8)$ & $21(30.4)$ \\
\hline Current use of synthetic DMARDs, $n$ (\%) & $80(57.1)$ & $38(53.5)$ & $42(60.9)$ \\
\hline Current use of biological DMARDs n (\%) & $45(32.1)$ & $18(25.4)$ & $27(39.1)$ \\
\hline Current use of glucocorticoids, n (\%) & $15(10.7)$ & $10(14.1)$ & $5(7.2)$ \\
\hline Ever use of glucocorticoids $\geq 5 \mathrm{mg} \geq 3 \mathrm{mg}, \mathrm{n}(\%)$ & $37(26.4)$ & $19(26.8)$ & $18(26.1)$ \\
\hline Use of calcium or vitamin D supplements,n (\%) & $17(12.1)$ & $16(22.5)$ & $1(1.4)$ \\
\hline Osteoporosis medication, n (\%) & $3(2.1)$ & $3(4.2)$ & 0 \\
\hline Previous low energy fracture, $\mathrm{n}(\%)$ & $9(6.4)$ & $6(8.5)$ & $3(4.3)$ \\
\hline
\end{tabular}

*Unless stated, results are mean $( \pm S D)$ for continuous variables or absolute values (percentages) for categorical variables.

Anti-TNFtherapy, anti-tumour necrosis factor therapy; BMI, body mass index; CRP, C-reactive protein;DAS-28, disease activity score for 28 joints with ESR; DMARD, disease modifyinganti rheumatic drug; ESR, erythrocyte sedimentation rate; HLA B 27, human leucocyteantigen B 27; MHAQ, Modified Health Assessment Questionnaire; NSAIDs, non-steroidalanti-inflammatory drugs; SJC 66, swollen joint count 66 joints; TJC 68, tenderjoint count 68 joints.

still included in any of the analyses for which they have the necessary information.

\section{RESULTS}

Demographic characteristics are presented in table 1. Mean \pm SD age was $52.4 \pm 10.3$ years and 71 (50.7\%) were women. The age of the included patients ranged from 23 to 74 years, and $60.7 \%$ were $>50$ years. Median
(IQR) disease duration was 7.8 (9.3) years. Bone density data are presented in table 2. Mean \pm SD BMD of the patients with PsA was $0.967 \pm 0.141 \mathrm{~g} / \mathrm{cm}^{2}$ at femoral neck, $1.017 \pm 0.148 \mathrm{~g} / \mathrm{cm}^{2}$ at total hip and $1.208 \pm 0.170$ $\mathrm{g} / \mathrm{cm}^{2}$ at lumbar spine $1-4$. The percentage of patients with PsA with $\mathrm{Z}$ score $\leq-1.0 \mathrm{SD}$ was comparable to the DXA reference population for the overall patients with PsA and for women separately. For men, there was an 
Table 2 Bone mineral density (BMD) of the patients with psoriatic arthritis (PsA).

\begin{tabular}{|c|c|c|c|c|}
\hline & Femoral neck & Total hip & Lumbar spine 1-4 & Any site \\
\hline \multicolumn{5}{|l|}{$\begin{array}{l}\text { Overall patients with } \\
\text { PsA }(N=140)\end{array}$} \\
\hline BMD g/cm² (SD) & $0.967(0.141)$ & $1.017(0.148)$ & $1.208(0.170)$ & - \\
\hline T score $(95 \% \mathrm{Cl})$ & $-0.68(-0.87$ to -0.49$)$ & $-0.25(-0.44$ to -0.06$)$ & $0.10(-0.15$ to 0.33$)$ & - \\
\hline Z score $(95 \% \mathrm{Cl})$ & $-0.11(-0.26$ to 0.06$)$ & $-0.05(-0.22$ to 0.12$)$ & $0.14(-0.08$ to 0.35$)$ & - \\
\hline $\begin{array}{l}\text { T score } \leq-2.5 \\
\mathrm{n}(\%, 95 \% \mathrm{Cl})\end{array}$ & $6(4.3 \%, 1.6 \%$ to $9.1 \%)$ & $2(1.4 \%, 0.2 \%$ to $5.1 \%)$ & $3(2.1 \%, 0.4 \%$ to $6.1 \%)$ & $9(6.4 \%, 3.0 \%$ to $11.9 \%)$ \\
\hline $\begin{array}{l}\text { Z score } \leq-1.0 \\
\text { n }(\%, 95 \% \mathrm{Cl})\end{array}$ & $\begin{array}{l}28(20.0 \%, \\
13.7 \% \text { to } 27.6 \%)\end{array}$ & $\begin{array}{l}25(17.9 \%, \\
11.9 \% \text { to } 25.2 \%)\end{array}$ & $25(17.9 \%, 11.9$ to $25.2 \%)$ & $\begin{array}{l}43(30.7 \%, \\
23.2 \% \text { to } 39.1 \%)\end{array}$ \\
\hline \multicolumn{5}{|l|}{ Females $(\mathrm{N}=71)$} \\
\hline $\mathrm{BMD} \mathrm{g} / \mathrm{cm}^{2}(\mathrm{SD})$ & $0.954(0.151)$ & $0.987(0.161)$ & $1.188(0.184)$ & - \\
\hline T score $(95 \% \mathrm{Cl})$ & $-0.69(-0.98$ to -0.39$)$ & $-0.15(-0.45$ to 0.16$)$ & $0.11(-0.26$ to 0.47$)$ & - \\
\hline Z score $(95 \% \mathrm{Cl})$ & $0.05(-0.19$ to 0.29$)$ & $0.12(-0.15$ to 0.40$)$ & 0.345 (0.02 to 0.66$)$ & - \\
\hline $\begin{array}{l}\text { T score } \leq-2.5 \\
\text { n }(\%, 95 \% \mathrm{Cl})\end{array}$ & $5(7.0 \%, 2.3 \%$ to $15.7 \%)$ & $2(2.8 \%, 0.3 \%$ to $9.8 \%)$ & $1(1.4 \%, 0.0 \%$ to $7.6 \%)$ & $6(8.5 \%, 3.2 \%$ to $17.5 \%)$ \\
\hline $\begin{array}{l}\text { Z score } \leq-1.0 \\
\text { n }(\%, 95 \% \mathrm{Cl})\end{array}$ & $\begin{array}{l}10(14.1 \%, \\
7.0 \% \text { to } 24.4 \%)\end{array}$ & $\begin{array}{l}12(16.9 \%, \\
9.0 \% \text { to } 27.7 \%)\end{array}$ & $\begin{array}{l}10(14.1 \%, \\
7.0 \% \text { to } 24.4 \%)\end{array}$ & $\begin{array}{l}16(22.5 \%, \\
13.5 \% \text { to } 34.0 \%)\end{array}$ \\
\hline \multicolumn{5}{|l|}{ Males $(\mathrm{N}=69)$} \\
\hline BMD g/cm² (SD) & $0.981(0.130)$ & $1.047(0.128)$ & $1.229(0.152)$ & - \\
\hline T score $(95 \% \mathrm{Cl})$ & $-0.67(-0.91$ to -0.43$)$ & $-0.36(-0.58$ to -0.15$)$ & $0.09(-0.21$ to 0.39$)$ & - \\
\hline Z score $(95 \% \mathrm{Cl})$ & $-0.27(-0.48$ to -0.05$)$ & $-0.24(-0.43$ to -0.04$)$ & $-0.09(-0.36$ to 0.21$)$ & - \\
\hline $\begin{array}{l}\text { T score } \leq-2.5 \\
\mathrm{n}(\%, 95 \% \mathrm{Cl})\end{array}$ & $1(1.4 \%, 0.0 \%$ to $7.8 \%)$ & $0(0 \%, 0.0 \%$ to $5.2 \%)$ & $2(2.9 \%, 0.4 \%$ to $10.1 \%)$ & $3(4.3 \%, 0.9 \%$ to $12.2 \%)$ \\
\hline $\begin{array}{l}\text { Z score } \leq-1.0 \\
n(\%, 95 \% \mathrm{Cl})\end{array}$ & $\begin{array}{l}18(26.1 \%, \\
16.3 \% \text { to } 38.1 \%)\end{array}$ & $\begin{array}{l}13(18.8 \%, \\
10.4 \% \text { to } 30.1 \%)\end{array}$ & $\begin{array}{l}15(21.7 \%, \\
12.7 \% \text { to } 33.3 \%)\end{array}$ & $\begin{array}{l}27(39.1 \%, \\
27.6 \% \text { to } 51.6 \%)\end{array}$ \\
\hline
\end{tabular}

95\% Cls for the proportion of patients with $T$ score $\leq 2.5$ and $Z$ score $\leq 1.0$ were calculated by using a binomial test.

increased proportion with low BMD at all three anatomical locations compared with the expected value of $16 \%$ in the reference population, however only statistically significant for femoral neck $(26.1 \%$ (95\% CI $16.3 \%$ to $38.1 \%$ ), $\mathrm{p}=0.02$ ) (figure 1). As shown in table 2, $\mathrm{T}$ score $\leq-2.5$ was found in six $(4.3 \%)$ patients at femoral neck,

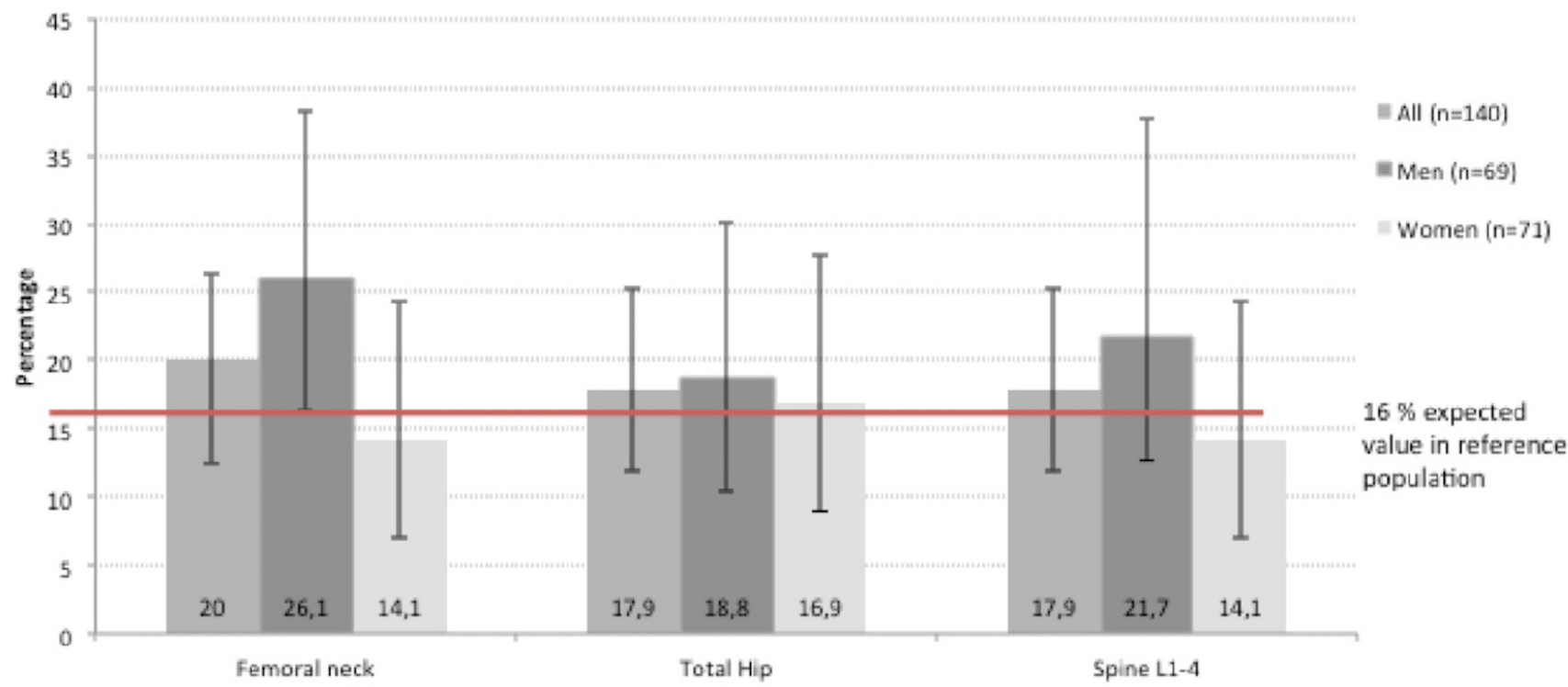

Figure 1 Percentages of patients with psoriatic arthritis with low Z score (95\% Cl). 
two $(1.4 \%)$ at total hip and three $(2.1 \%)$ at lumbar spine (table 2). At any site, nine (6.4\%) patients had osteoporosis, three men and six women. A normal BMD both in the lumbar spine and hip (femoral neck and total hip) was found in $55.7 \%$ of patients. Patients with a normal BMD were younger $(49.3 \pm 9.2$ vs $56.3 \pm 10.2$ years, $\mathrm{p}<0.001)$ and had higher BMI $\left(28.8 \pm 4.6\right.$ vs $\left.27.3 \pm 3.6 \mathrm{~kg} / \mathrm{m}^{2}, \mathrm{p}=0.03\right)$, but were similar in terms of disease duration, disease activity and outcome measures. There was no difference in $\mathrm{T}$ score between users and non-users of glucocorticoids and biological DMARDs for all three measurement sites. Post-hoc analyses calculating $\mathrm{T}$ score only in postmenopausal women and men 50 years or older $(\mathrm{N}=76)$ gave a mean T score (95\% CI) of $-0.32(-0.62$ to -0.03$)$ at lumbar spine, $-0.69(-0.90$ to -0.50$)$ at total hip and $-1.19(-1.41$ to -0.97$)$ at femoral neck. In this subgroup, eight patients had osteoporosis according to T score (two patients at lumbar spine, two patients at total hip and six patients at femoral neck).

Multivariable linear regression showed a negative association between BMD and age, and a positive association between BMD and BMI for the overall series, but not with ESR or swollen joint count 66 (online supplementary table). No association was found between BMD and use of medications (DMARDs, TNF inhibitors, glucocorticoids, NSAIDs or anti-osteoporotic medication) or other disease activity measures (DAS28, MHAQ, BASDAI, MASES, PGA or IGA). For men, ESR was associated with total hip BMD $(p<0.01)$ and lumbar spine BMD $(p<0.01)$. Swollen joint count 66 showed significant association with BMD in the univariable analysis; however, the association was only significant for BMD at lumbar spine of women in the multivariable analyses $(\mathrm{p}=0.02)$.

\section{DISCUSSION}

In this cross-sectional study, we found a low prevalence of osteoporosis and low BMD in PsA outpatients. Thus according to our data generalised bone loss does not seem to be a major comorbidity in patients with PsA in the biological treatment era. Our data showed that Norwegian outpatients with PsA had similar age, weight and gender-adjusted BMD (Z score) compared with the normative reference population data. However, in the male group there was a slightly higher proportion of patients with low $\mathrm{Z}$ score compared with the expected reference population. Our findings support other publications reporting comparable BMD in patients with PsA and the general population. ${ }^{911-131819}$ In a recent population-based study from Norway, BMD in patients with PsA was also found to be comparable to the background population. ${ }^{20}$

There is great diversity in the reported proportion of osteoporosis in PsA, ranging from $1.4 \%$ to $68.8 \%$. $^{79} 1921$ The findings from this study, of $6.4 \%$, lie in the lower range of the results reported. Comparing results across studies is difficult as outcomes, patient selections and control groups differ. ${ }^{6}$ A study from 2001 reported a prevalence of osteoporosis in Italian patients with PsA of $30 \%$; however, this was before the biological therapy era. ${ }^{7}$ Disease activity of patients with PsA is probably lower today than it was 17 years ago, with greater focus on early diagnosis and more effective treatment options. A frequency of osteoporosis of $16 \%$ was reported in a study including premenopausal and postmenopausal female and male patients with PsA from an outpatient clinic. ${ }^{9}$ Grazio et al reported a similar frequency of osteoporosis to our data, along with a negative correlation with MHAQ. ${ }^{19}$ In the present study, we did not discover any association between BMD and disease duration, disease activity or outcome measures, except for subgroup analyses of men that showed an association between BMD and ESR. However, the disease activity of the patients in the present study was low, with a median 66 swollen joint count of 0 , as well as low CRP and ESR. This is what would be expected in a contemporary clinic population as doctors adhere to the goal of getting patients to the lowest possible disease activity. Also, in Norway healthcare is publicly funded and the use of biological DMARDs is liberal. Very low disease activity and high remission rates were also shown in patients with RA in the Norwegian ARCTIC study from 2016. ${ }^{22}$ Another Norwegian study showed a twofold increase in remission rates in patients with RA between 2000 and 2010, with more and earlier use of synthetic and biological DMARDs. ${ }^{23}$ However, the low disease activity of this PsA population may explain why no association between BMD and disease activity measures were found in this study.

Based on the existing data, it seems that the risk of osteoporosis is lower in PsA than in RA. In normal bone, the osteoclast-mediated bone resorption is followed by a replacement of the resorbed bone by osteoblasts. In spondyloarthropathies, including PsA, the so-called 'coupling' of bone formation and resorption is deregulated such that there is local loss of bone at the enthesal insertion sites, and excessive bone formation in periosteal sites adjacent to the sites of bone erosion. The characteristic skeletal changes that occur are results of this endochondral ossification, in which new bone is formed by replacement of cartilaginous matrix. ${ }^{24}$ This enhanced bone formation at sites of inflammation is a typical feature of PsA and the other spondyloarthropaties compared with RA. This difference in pathophysiological mechanism between the spondyloarthropaties and RA may explain the difference in bone density reported in the literature. Further, clinical differences such as age of onset, the potential for more intermittent inflammation and less use of glucocorticoids in PsA compared with RA may also influence the difference in risk of systemic bone loss. In our outpatient clinic, we have previously reported current prednisolone treatment in $13.7 \%$ of all the patients with PsA compared with $54.3 \%$ of all the patients with RA. ${ }^{25}$ In the present study, only $11 \%$ were currently using glucocorticoids.

TNF inhibitors have been shown to increase BMD in lumbar spine and hip in spondyloarthropaties. ${ }^{26-28}$ Some relate this to a possible increase in new bone formation 
after TNF inhibitor treatment, which can increase BMD in the spine; however, similar results were also found in a study that adjusted for radiographic progression. ${ }^{29}$ This suggests that TNF inhibitors improve bone metabolism in spondyloarthropaties by relatively increasing the effect of osteoblasts and reducing the activity of osteoclasts. ${ }^{30}$ In our data, more than one-third of the patients with PsA were currently using TNF inhibitors, and therefore may be protected from generalised bone loss. However, no difference in $\mathrm{T}$ score between users and non-users of biological DMARDs was found in this study.

The concept of bone strength has expanded in the recent years to also include the quality of the bone, which includes factors such as microarchitecture, the quality of collagen and the speed of bone turnover. ${ }^{31} \mathrm{In}$ patients with PsA, a higher cortical porosity and lower cortical bone density of the distal radius on high resolution CT, despite a normal BMD, has been reported. ${ }^{32}$ This may affect the cortical bone quality and predispose the bone to fractures. In a recent population-based study, a small but significantly increased risk of all fractures was reported in patients with PsA and psoriasis. ${ }^{33}$ In our study, we did not find a high prevalence of self-reported fragility fractures $(6.4 \%)$.

Over the last decade, the rheumatology community has become more aware of the importance of comorbidities contributing to outcome in patients with chronic inflammatory rheumatic disorders, including PsA. This is addressed in the European League Against Rheumatism initiative aiming to improve the prevention of comorbidities in rheumatic disorders. ${ }^{34}$ A recent review article recommends that general screening for osteoporosis should be followed in patients with PsA, ${ }^{35}$ except for patients on glucocorticoids, where the American College of Rheumatology recommendations should be followed. ${ }^{36}$

The main strengths of this study are the use of objective criteria for PsA, patients recruited from a contemporary standard care outpatient clinic and a selection of patients that seems to reflect the cohort of PsA outpatients in southern Norway. Furthermore, extensive clinical data on the study cohort are included. The main limitation is that we do not have a control group recruited from the background population. However, data indicate that the reference population provided by the DXA manufacturer reflects the bone density of the background Norwegian population. A study from western Norway found comparable BMD in the investigated population and the reference data provided by the DXA manufacturer, except for lower BMD for men at total hip in the examined population. ${ }^{37}$ Further, a study from Oslo, Norway, also found comparable BMD in a reference population compared with Lunar DXA European/US reference population. ${ }^{38}$ Another limitation of this study is that we did not examine radiological images of the patients with PsA to control for syndesmophytes in the spine or new bone formation of the hip area, or calcifications of the aorta, which may influence the BMD values at these sites. Also, for the subgroup analyses we had only 71 women and 69 men, which may have led to the higher proportion of low $\mathrm{Z}$ score observed in men failing to reach statistical significance (type 2 error).

\section{CONCLUSION}

Data from this study suggest that low BMD is not a significant clinical problem in patients with PsA in the biological treatment era. The results therefore support the recommendation that patients with PsA may follow guidelines for osteoporosis assessment developed for the general population.

\section{Author affiliations}

${ }^{1}$ Department of Rheumatology, St. Olavs Hospital, Trondheim, Norway

${ }^{2}$ Department of Neuromedicine and Movement Science, Norwegian University of Science and Technology, Trondheim, Norway

${ }^{3}$ Department of Rheumatology, Hospital of Southern Norway Trust, Kristiansand, Norway

${ }^{4}$ Department of Rheumatology, Martina Hansens Hospital, Bærum, Norway ${ }^{5}$ Unit for Applied Clinical Research, Norwegian University of Science and Technology, Trondheim, Norway

${ }^{6}$ Department of Rheumatology, Allergy and Immunology, University of California San Diego, San Diego, California, USA

${ }^{7}$ Department of of Public Health and Nursing, Norwegian University of Science and Technology, Trondheim, Norway

Acknowledgements The authors thank the patients for participating in this study and the local rheumatology staff at the Hospital of Southern Norway Trust, Kristiansand, for data collection, and in particular Hanne Vestaby, Kari Hansen Berg, Solfrid Jaatun and Eli Jensen.

Contributors GH and MH: conception, collection of data, planning and design, statistical analysis, interpretation of data and writing. AMG: statistical analyses, interpretation of data and writing. BM: collection of data and writing. ØS: statistical analyses and writing. $\mathrm{AK}$ and $\mathrm{BHG}$ : interpretation of data and writing. $\mathrm{AD}$ : collection of data, interpretation of data and writing.

Funding statement The study was funded by The Liaison Committee between the Central Norway Regional Health Authority (RHA) and the Norwegian University of Science and Technology (NTNU).

Competing interests None declared.

Patient consent Not required.

Ethics approval Regional Committee for Medical Research Ethics in SouthEastern Norway (REK number: 2012/101).

Provenance and peer review Not commissioned; externally peer reviewed.

Open access This is an Open Access article distributed in accordance with the Creative Commons Attribution Non Commercial (CC BY-NC 4.0) license, which permits others to distribute, remix, adapt, build upon this work non-commercially, and license their derivative works on different terms, provided the original work is properly cited and the use is non-commercial. See: http://creativecommons.org/ licenses/by-nc/4.0/

(c) Article author(s) (or their employer(s) unless otherwise stated in the text of the article) 2018. All rights reserved. No commercial use is permitted unless otherwise expressly granted.

\section{REFERENCES}

1. Kruithof E, Baeten D, De Rycke L, et al. Synovial histopathology of psoriatic arthritis, both oligo- and polyarticular, resembles spondyloarthropathy more than it does rheumatoid arthritis. Arthritis Res Ther 2005;7:R569-80.

2. Gough AK, Lilley J, Eyre S, et al. Generalised bone loss in patients with early rheumatoid arthritis. Lancet 1994;344:23-7.

3. Güler-Yüksel M, Allaart CF, Goekoop-Ruiterman YP, et al. Changes in hand and generalised bone mineral density in patients with recentonset rheumatoid arthritis. Ann Rheum Dis 2009;68:330-6. 
4. Haugeberg G, Helgetveit KB, Førre Ø, et al. Generalized bone loss in early rheumatoid arthritis patients followed for ten years in the biologic treatment era. BMC Musculoskelet Disord 2014;15:289.

5. Haugeberg G, Ørstavik RE, Uhlig T, et al. Bone loss in patients with rheumatoid arthritis: results from a population-based cohort of 366 patients followed up for two years. Arthritis Rheum 2002;46:1720-8.

6. Chandran S, Aldei A, Johnson SR, et al. Prevalence and risk factors of low bone mineral density in psoriatic arthritis: A systematic review. Semin Arthritis Rheum 2016;46:174-82.

7. Frediani B, Allegri A, Falsetti $\mathrm{P}$, et al. Bone mineral density in patients with psoriatic arthritis. J Rheumatol 2001;28:138-43.

8. Reddy SM, Anandarajah AP, Fisher MC, et al. Comparative analysis of disease activity measures, use of biologic agents, body mass index, radiographic features, and bone density in psoriatic arthritis and rheumatoid arthritis patients followed in a large U.S. disease registry. J Rheumatol 2010;37:2566-72.

9. Busquets N, Vaquero CG, Moreno JR, et al. Bone mineral density status and frequency of osteoporosis and clinical fractures in 155 patients with psoriatic arthritis followed in a university hospital. Reumatol Clin 2014;10:89-93.

10. Cortet B, Trouvé MH, Flipo RM. Bone involvement in psoriatic arthritis. J Rheumatol 2002;29:1107-8.

11. Nolla JM, Fiter J, Rozadilla A, et al. Bone mineral density in patients with peripheral psoriatic arthritis. Rev Rhum Engl Ed 1999;66:457-61.

12. Pedreira PG, Pinheiro MM, Szejnfeld VL. Bone mineral density and body composition in postmenopausal women with psoriasis and psoriatic arthritis. Arthritis Res Ther 2011;13:R16.

13. Riesco M, Manzano F, Font P, et al. Osteoporosis in psoriatic arthritis: an assessment of densitometry and fragility fractures. Clin Rheumatol 2013;32:1799-804.

14. Taylor W, Gladman D, Helliwell P, et al. Classification criteria for psoriatic arthritis: development of new criteria from a large international study. Arthritis Rheum 2006;54:2665-73.

15. Michelsen B, Diamantopoulos AP, Hammer HB, et al. Ultrasonographic evaluation in psoriatic arthritis is of major importance in evaluating disease activity. Ann Rheum Dis 2016;75:2108-13

16. Michelsen B, Diamantopoulos AP, Høiberg HK, et al. Need for improvement in current treatment of psoriatic arthritis: study of an outpatient clinic population. J Rheumatol 2017;44:431-6.

17. Assessment of fracture risk and its application to screening for postmenopausal osteoporosis. Report of a WHO Study Group. World Health Organ Tech Rep Ser 1994;843:1-129.

18. Del Puente A, Esposito $A$, Costa $L$, et al. Fragility fractures in patients with psoriatic arthritis. J Rheumatol Suppl 2015;93:36-9.

19. Grazio S, Cvijetić S, Vlak T, et al. Osteoporosis in psoriatic arthritis: is there any? Wien Klin Wochenschr 2011;123(23-24):743-50.

20. Gulati AM, Hoff M, $\varnothing \mathrm{S}$, et al. Bone mineral density in psoriatic arthritis - data from the Nord-Trøndelag Health Study. RMD Open. In Press. 2016.

21. Attia EA, Khafagy A, Abdel-Raheem S, et al. Assessment of osteoporosis in psoriasis with and without arthritis: correlation with disease severity. Int J Dermatol 2011;50:30-5.
22. Haavardsholm EA, Aga AB, Olsen IC, et al. Ultrasound in management of rheumatoid arthritis: ARCTIC randomised controlled strategy trial. BMJ 2016;354:i4205.

23. Aga $A B$, Lie $E$, Uhlig $T$, et al. Time trends in disease activity, response and remission rates in rheumatoid arthritis during the past decade: results from the NOR-DMARD study 2000-2010. Ann Rheum Dis 2015;74:381-8.

24. Goldring SR. Osteoimmunology and bone homeostasis: relevance to spondyloarthritis. Curr Rheumatol Rep 2013;15:342

25. Michelsen B, Fiane R, Diamantopoulos AP, et al. A comparison of disease burden in rheumatoid arthritis, psoriatic arthritis and axial spondyloarthritis. PLoS One 2015;10:e0123582.

26. Briot K, Gossec L, Kolta S, et al. Prospective assessment of body weight, body composition, and bone density changes in patients with spondyloarthropathy receiving anti-tumor necrosis factor-alpha treatment. J Rheumatol 2008;35:855-61.

27. Durnez A, Paternotte S, Fechtenbaum J, et al. Increase in bone density in patients with spondyloarthritis during anti-tumor necrosis factor therapy: 6-year followup study. J Rheumatol 2013;40:1712-8.

28. Arends S, Spoorenberg A, Brouwer E, et al. Clinical studies on bone-related outcome and the effect of TNF- $\alpha$ blocking therapy in ankylosing spondylitis. Curr Opin Rheumatol 2014;26:259-68.

29. Kang KY, Ju JH, Park SH, et al. The paradoxical effects of TNF inhibitors on bone mineral density and radiographic progression in patients with ankylosing spondylitis. Rheumatology 2013;52:718-26.

30. Siu S, Haraoui B, Bissonnette R, et al. Meta-analysis of tumor necrosis factor inhibitors and glucocorticoids on bone density in rheumatoid arthritis and ankylosing spondylitis trials. Arthritis Care Res 2015;67:754-64.

31. Licata A. Bone density vs bone quality: what's a clinician to do? Cleve Clin J Med 2009;76:331-6.

32. Zhu TY, Griffith JF, Qin L, et al. Density, structure, and strength of the distal radius in patients with psoriatic arthritis: the role of inflammation and cardiovascular risk factors. Osteoporos Int 2015;26:261-72.

33. Ogdie A, Harter L, Shin D, et al. The risk of fracture among patients with psoriatic arthritis and psoriasis: a population-based study. Ann Rheum Dis 2017;76:882-5.

34. Baillet A, Gossec L, Carmona L, et al. Points to consider for reporting, screening for and preventing selected comorbidities in chronic inflammatory rheumatic diseases in daily practice: a EULAR initiative. Ann Rheum Dis 2016;75:965-73.

35. Ogdie A, Schwartzman S, Husni ME. Recognizing and managing comorbidities in psoriatic arthritis. Curr Opin Rheumatol 2015;27:118-26.

36. Grossman JM, Gordon R, Ranganath VK, et al. American college of rheumatology 2010 recommendations for the prevention and treatment of glucocorticoid-induced osteoporosis. Arthritis Care Res 2010;62:1515-26.

37. Gjesdal CG, Aanderud SJ, Haga HJ, et al. Femoral and wholebody bone mineral density in middle-aged and older Norwegian men and women: suitability of the reference values. Osteoporos Int 2004:15:525-34.

38. Falch JA, Meyer HE. [Bone mineral density measured by dual $\mathrm{X}$-ray absorptiometry. A reference material from Oslo]. Tidsskr Nor Laegeforen 1996;116:2299-302. 